\title{
Salud Mental Infantil: de qué hablamos al referirnos al niño en psicopatología. Prevención y clínica en psicopatología infantil.
}

Infantile Mental Health: what are we talking about whe referring child in psychopathology. Prevention and clinics in infantile psychopathology.

\section{Federico Menéndez Osorio ${ }^{\text {a }}$.}

${ }^{a}$ Psiquiatra.

Correspondencia: Federico Menéndez Osorio (femeos@telefonica.net)

Recibido: 02/07/2013; aceptado: 06/12/2013

RESUMEN: Toda práctica psicopatológica presupone una teoría y una concepción del sujeto/objeto de su estudio. En el caso de la clínica infantil este presupuesto se obvia al existir una visión del niño dominada por los estereotipos y la ignorancia. Saber de la infancia es dar cuenta de su historia, de su estatuto como sujeto, de su condición psíquica, biológica, social, etc.

Se señalan los dos registros e instrumentos específicos y diferenciales de nuestra práctica clínica: el lenguaje y la subjetividad. De estos dos registros se derivará el tipo de intervención a realizar tanto en la prevención como en la práctica clínica.

Respecto a la prevención, cuestionando el concepto de vulnerabilidad como lo anómalo, dando entrada al concepto de resiliencia como necesario para entender lo preventivo. Asimismo se replantea el falso mimetismo con el modelo de prevención médicobiológico, dado lo específico y propio de lo psíquico.

Respecto a la práctica clínica, se formulan varios puntos, cuestionando el reduccionismo cientificista -que no científico- de los conocimientos en lo psíquico; la confusión diagnóstica de síntoma con enfermedad; la patologización de las conductas, etc. entre otros replanteamientos de la clínica psicopatológica.

Finalmente, hemos de proporcionar al niño un lugar y un espacio donde pueda dar cuenta de la expresión de su sufrimiento psíquico.

PALABRAS CLAVE: Salud Mental Infantil. Prevención. Clínica. Infancia. Subjetividad. Lenguaje. Psicopatología infantil.
ABSTRACT: Every psychopathological praxis involves a theory and a conception of the individual, the object of its study. As for the infantile clinics, this assumption is left out by a view of the child dominated by stereotypes and ignorance. Knowledge of childhood represents to account for the story, the individual statute, his/her psychical, biological, social... condition.

The two specific and differential records and tools of our clinical praxis are marked: language and subjectivity. The recommendable intervention for prevention and clinical praxis is shaped upon those. With regard to prevention, by questioning the concept of vulnerability as the anomalous, and by introducing the concept of resilience as needed to understand the preventive praxis. We also rethink the false mimicry with the medical-biological model of prevention, given the specificity and genuine condition of the psychical sphere.

In relation to the clinical praxis, several topics are formulated, questioning the 'scientificist -not scientific- reductionism' of the psychical knowledge; the diagnostic confusion of the symptom with the disease; the 'pathologization' of behaviors, etc., among other reconsiderations of the psychopathological clinics.

Finally, we have to supply the children with a place and a space where they can account for the expression of their psychical suffering.

KEY WORDS: Infantile Mental Health. Prevention. Clinics. Subjectivity. Language. Infantile Psychopathology. 
ORIGINALES Y REVISIONES

\section{I.- De qué hablamos cuando hablamos del niño en psicopatología.}

Toda práctica psicopatológica presupone y sostiene una teoría y una concepción previa del objeto de estudio, en nuestro caso, el niño. Cuando no se plantea este presupuesto, al no saber que se está manejado por una teoría, no se tiene control sobre la teoría y los conceptos que se manejan y esto lleva a serios problemas en la práctica clínica (1).

Como afirmaba Kant (2): “... al no precisar suficientemente su concepto, ese autor hablaba o pensaba incluso de forma contraria a su objetivo..." (p. 310) "... la verdad consiste en la conformidad de un conocimiento con su objeto... pues un conocimiento que no coincide con el objeto al que es referido es falso..." (p. 98).

Por esto es importante tener claro los conceptos. Y esta advertencia es muy oportuna al abordar la clínica infantil, ante el desconocimiento y los estereotipos sobre la infancia.

Si al hablar de la clínica del adulto se comienza por entender que es el ser humano adulto: su condición biológica, psicológica, social, antropológica, cultural, etc., al referirse a la clínica en S.M.I. será importante comenzar por la base, lo primero o básico del objeto de estudio específico: ¿qué es el niño?, es decir, su estatuto como sujeto, su entidad, su historia, su ser biológico, psicológico y social, etc., fundamentos para entender la psicopatología infantil.

\section{Historia de la infancia: función y valor del niño}

Aunque se utiliza el término de infancia como etapa cronológica, es preciso señalar que se hace referencia a la infancia como lo genérico, porque cada niño -al igual que todo ser humano- es diferente y tiene diferentes reacciones ante los mismos estímulos. Como afirma Spinke Jonze: “... el problema es que se ha extendido la idea de que los niños son sólo de una determinada manera." (3).

El concepto de infancia aparece, según Ph. Ariès (4) en el S. XV al XVII, como un constructo de la historia moderna. La infancia, hasta entonces, estaba subsumida y diluida como un todo del adulto.

Para algunos, hablar de la infancia es apelar a un sentimiento de ternura, a una visión rosa, cándida, inocente y angelical del mundo infantil. Frente a esta idealización, hay otra realidad del niño. La historia de la infancia nos muestra la función tan distinta que el niño ha tenido a lo largo de los tiempos. Así, por ejemplo, etapa como la adolescencia, es algo reciente, que no existió anteriormente como tal. 
El niño como ser social, no queda fuera de las leyes del intercambio, de la economía y de la producción.

Siguiendo a Lloyd de Mause (5), si en una época fue el infanticidio o el abandono en las amas de cría, la forma de responder a lo que suponía el valor y papel del niño; en otros tiempos, fue la explotación laboral, en los albores de la sociedad industrial; y hoy lo es, como consumidor en nuestra sociedad, aunque se den todavía formas y desarrollos muy desiguales (manteniéndose en no pocos lugares, la explotación, el maltrato y el abandono).

La sociedad de consumo actual nos muestra el auge que ha alcanzado el emporio económico montado sobre y en torno al niño: moda infantil, juguetería, turismo-ocio, educación, salud, etc. Especialismos de todo tipo de consumo infantil. De tal manera que si el niño dejase de consumir o se anulase el gasto consumista infantil, tendríamos una quiebra de la economía mundial.

Como botón de muestra valgan algunas cifras ilustrativas del gasto consumista infantil:

- En USA (1985) (6)

$\circ$ Adolescente/por año

- 5,7 billones de pesetas en ropa, videojuegos, discos, golosinas.

- 1,56 billones de pesetas en juguetes.

- En INGLATERRA (6)

- Niños de 7 a 15 años/por año

- 66.560 millones de pesetas en ropa

- 22.800 millones de pesetas en patatas fritas

- 44.184 millones de pesetas en dulces

- En ESPAÑA (Revista El Publicista $\mathrm{n}^{\circ}$ 36. Diciembre 2000)

$\circ$ Inversión en publicidad para niños $=38.372$ millones de pesetas

Estas cifras nos muestran que, además de receptor y dador de amor, cariño y dulzura, así como continuador de la especie, el niño actual tiene también una realidad muy material y necesaria en el proceso productivo de nuestra sociedad y esto es importante a valorar y a tener en cuenta para quienes se interesen y quieran analizar "las causas del niño" (7).

Es preciso añadir y señalar que todo lo anterior se refiere al niño occidental y de nuestra sociedad, porque la realidad de otros niños y otros países o zonas, es muy diferente y dramática (115 millones de niños hacen trabajos que la OIT considera peligrosos) (8) 
ORIGINALES Y REVISIONES

\section{Visiones de la infancia}

Hay un enfoque habitual de ver al niño desde una visión paternalista y adultomórfica, como reservorio de ideales e ilusiones, paraíso de ternura y época dorada en la que la naturaleza humana se refleja como bondad, inocencia y candor.

Todo lo cual contrasta con la otra realidad que se nos presenta más recientemente del niño agresivo, despótico, delincuente, asesino... (no faltan noticias periodísticas y de los medios de difusión pródigas en mostrar casos y sucesos relativos a actos de este tipo realizados por niños).

El niño no es malo, ni bueno por naturaleza. Es lo uno y lo otro. Tiene la capacidad de hacer el bien y el mal, ambos inscritos en todo ser humano dotado de razón. Como refiere Winnicott, "En el niño hay amor y odio, bien y mal... y estos sentimientos no son experimentados con mayor violencia por el adulto que por el niño pequeño..." (9). Todos los padres saben como un niño puede ser cariñoso y encantador, o bien, caprichoso, tiránico...

Dada la idea de la inocencia y del estado de naturaleza en el que está el niño, tendemos a creer que no discierne el bien y el mal y que está en el limbo o no se entera de todo aquello que le circunda o atañe. Ya Margarita Yourcenar señalaba: "Nuestra época ignora o niega el talento de la infancia" (10).

A su nivel, dada su condición particular y singular, su capacidad, su cultura, etc. el niño capta, comprende, rechaza, hace, deshace, imita, integra-asimila y se identifica. Es preciso un apunte clínico al respecto de la imitación y de la identificación. Son términos que se confunden y erróneamente se manejan conceptualmente al abordar el saber sobre el niño (y el adulto), con las consecuencias prácticas que ello conlleva y la ligereza de conceptos que supone.

Imita el mono, en el ser humano se da un proceso de identificación y asimilación. El percibir, sentir, la conciencia, etc. no son un acto de simple registro imitativo o especular (propio del animal); en el humano es intelectivo, simbólico, creativo, singular y particular.

Lo mismo sucede al confundir la empatía atribuida a las neuronas espejo, con la simpatía que, tanto a nivel de los circuitos cerebrales como de la elaboración mental, tiene diferentes registros y fenómenos explicativos.

Todo esto, si no se tiene en cuenta, va a tener repercusiones en la clínica y en la observación y valoración del acto del niño.

\section{El niño como sujeto}

Hay una resistencia a reconocer en el niño que es sujeto de su historia. No entender que el niño es sujeto de su historia es relegarlo a objeto ahistórico sin 
ORIGINALES Y REVISIONES

capacidad de deseo, volver a las visiones organicistas de pura necesidad biológica o a las visiones dulzonas-humanistas prestas a salvar al niño sin uso de razón y lanzarlo al limbo de los justos.

Este desconocimiento o negación de la realidad del mundo infantil, nos lo vamos a encontrar también en relación al campo de lo psíquico.

Hasta no hace mucho se pensaba que el niño no tenía problemas mentales (sólo muy recientemente se aprobó la especialidad de psiquiatría infantil), en tal caso, los malestares o trastornos que pudiera presentar, serían una falta de la naturaleza, sea ésta biológica, o del medio, educativa, etc.

Al niño se le excluye así y se ignora que sea capaz de sufrir y gozar, sentir y padecer, deprimirse y exaltarse, delirar y razonar..., es decir, tener un psiquismo que al igual que los demás mortales $-\mathrm{y}$ a su propio nivel- se pregunta sobre los temas de todo lo humano: el amor, el sexo y la muerte. Asimismo, el poder padecer todo cuanto atañe al existir, entre ello, al desvarío.

Cierto que ahora y por razones similares a las expuestas, está deslizándose un fenómeno opuesto: si antes había un desconocimiento e ignorancia sobre los problemas mentales del niño, ahora hay una psicopatologización y medicalización de la vida cotidiana, del sufrimiento, de los malestares, de los problemas y de las relaciones con el saber o con los otros... Toda conducta del niño, si no encaja con una norma, puede ser diagnosticada patológica por los manuales al uso... y lo que se escape ya entrará en los códigos Z (11).

Antes por ignorancia, ahora por patologizar toda conducta, en definitiva, el niño sigue excluido de su capacidad de ser y de la expresión de su sufrimiento psíquico.

Se obvia con todo ellos las preguntas e interrogantes acerca de las conductas del niño, de cómo se confronta en tanto sujeto, a la vida (como todo humano), a su deseo y a su goce, es decir, el no excluirlo de la ética y del existir.

Estas formas particulares de arreglárselas con su deseo y su goce, se van a manifestar en las formaciones sintomáticas, en la angustia, en la depresión, en la queja, en la inhibición, en los problemas de aprendizaje, en definitiva, en la clínica.

La cuestión y el reto que se nos plantea es: cómo cada niño da cuenta y se las arregla con estas formas particulares y singulares, de la expresión de su demanda, de su deseo y de la inscripción de su goce. Éste es uno de los retos de la psicopatología.

Pero en lugar de dar una respuesta a esto, lo que nos encontramos es que ante todo desajuste, ante todo problema o dificultad en el niño, se le pone un diagnóstico, o mejor, se busca una lesión (cerebral, genética, neurotransmisores, etc.) y se le aplica un tratamiento ad-hoc. 
ORIGINALES Y REVISIONES

\section{La responsabilidad en el niño}

Esto nos lleva de la mano a otra reflexión en esta línea: la de la anulación del valor del acto del niño, de su responsabilidad.

La confusión entre responsabilidad y culpa hace más difícil comprender el problema. La responsabilidad no se agota en la culpa, es fundamento de ella. Como dice Günter Grass: "Hay que pasar del sentimiento de culpa al sentido de responsabilidad" (12).

Responsabilidad es valor del acto, que mi acto tiene un valor, me pertenece, depara consecuencias. La anulación de la responsabilidad en el niño, supone su borramiento como sujeto y el del valor de su acto, de su pertenencia. Para un niño ser responsable (= respondere), es saber que su acto en tanto expresión del ser (conducta, palabra, gesto, acción), le confiere un valor (positivo o negativo), conlleva una atribución (le pertenece, es de él, lo hizo), depara unas consecuencias (válidas o lesivas).

Quitar la responsabilidad al niño, es decir, el valor de su acto, supone abolirlo de pertenencia subjetiva y reducirlo a mero ente de la especie, haciendo equivalente su acto, al del animal, la planta o la piedra... Como afirma Ricoeur "Somos verdaderamente libres cuando somos responsables" (13).

No sería bueno quitarle al niño la capacidad del compromiso con los otros, de sostener la libertad y hacer propias las decisiones, aprender a tener autonomía y capacidad crítica, máxime cuando en casa, colegio, calle, etc. no se hace más que bombardearle y mandarle que tenga responsabilidad. El niño sabe bien de estas cosas y pide le den un lugar y un reconocimiento.

Es difícil hacer ver este valor del acto del niño cuando los propios términos de infantil, pueril, niñato, menor, hombrecito... suponen términos devaluados y usados despectivamente para descalificar lo dicho o las conductas de alguien.

\section{Las funciones parentales}

Hay otra pata sobre la que se apoya y pivota la responsabilidad del niño. Esta es la de los padres, en tanto responsables legales y a todos los efectos del niño.

De la responsabilidad de los padres y sobre todo de las funciones parentales, sería muy importante y necesaria una reflexión en profundidad -que rebasaría el propósito de este trabajo- porque en la clínica infantil con toda alegría y creyendo dar ciencia y dentro de los tratamientos, se dan a los padres pautas, normas, indicaciones de cómo actuar, es decir, de cómo ejercer la autoridad, la educación, el dar valores, conductas, etc. ¿De dónde les viene y dónde se forman los clínicos en tales saberes y 
ORIGINALES Y REVISIONES

conocimientos? ¿Es de su intuición y de la proyección de los propios ideales o valores, así como del buen parecer? No hay patente de corso para estos saberes.

Como lo expresa F. Pereña (14): "Para plantearse la responsabilidad de los padres en los trastornos psíquicos de los hijos hay que tener en cuenta, en primer lugar, que en la vida afectiva no funciona la articulación causa/efecto necesaria y universal y, en segundo lugar, que la respuesta en la que consiste la subjetividad del niño es imprevisible... ". Y añade "... nuestros hijos, son hijos de nuestra afecciones y de nuestras contradicciones, no son hijos sublimes de la mente... El adoctrinamiento pretende enseñar a los padres a legislar qué es un buen padre o una buena madre, qué conductas llevar... en lugar de valorar el sentir-se madre o hijo, en el modo de vínculo afectivo".

En este trabajo con los padres, es preciso restituirles un saber, ayudarles a encontrar y elaborar su función de padres, su compromiso en la elección hecha de de serlo.

Otro fenómeno a señalar es el declive de la figura paterna, la deriva del padre colegui, gestor, management -de su hijo- y las consecuencias derivadas de ello, como las agresiones o amenazas por parte de padres a profesores o, simplemente, a quien llame la atención a su hijo de una gamberrada o acto irrespetuoso, siendo vivido por ese padre como fallo de su gestión como padre y no como apoyos comunitarios (escuela, mayores, etc.) en la educación de todo niño.

Asimismo, es importante plantearse el papel de los "expertos", "técnicos", etc. que vienen a usurpar el saber intrínseco de todo padre o madre -construido a lo largo de siglos y generaciones- pretendiendo que van a "enseñar" y pautar cómo hay que amar, sufrir, gozar, sentir... como si esto se pudiese pautar y recetar.

El releer alguno de los escritores de otro tiempo acerca de las relaciones padre/hijo o comportamientos de los jóvenes, nos puede hacer reflexionar sobre la realidad que nos encontramos y que había sido descrita entonces. Cito, por poner simples ejemplos, tres autores españoles:

- Baltasar Gracián. El Criticón (15).

- José del Campillo y Cossío (16). Ilustrado asturiano que en el 1741 describía los comportamientos caprichosos de los hijos y la permisividad y complicidad de los padres.

- Ortega y Gasset (17) al referirse al hombre masa, al niño mimado y al señorito satisfecho.

\section{II.- Los registros de los psíquico}

Entre los diversos registros e instrumentos que dan cuenta de la psicopatología hay dos que atañen específicamente a nuestro quehacer: el registro del lenguaje y la subjetividad. 
Recojo de M. Bunge en su Filosofía para médicos: "Aunque no lo sepa, el médico de hecho filosofa todo el día... cuando razona bien, practica la lógica; cuando da por descontado que los pacientes, el personal, las cosas existen fuera de su conciencia, practica el realismo ingenuo; cuando supone que los genes y virus son reales, aunque no los perciba, adopta el realismo científico; cuando rechaza que las enfermedades tengan origen espiritual, suscribe una concepción materialista del mundo; y cuando presta una ayuda o en su práctica intenta curar sin dañar, está practicando una filosofía moral humanista... en resumen, el médico filosofa aunque sin saberlo" (18) (y aunque no le importe saberlo).

Pues bien, algo similar ocurre con estos dos registros, el lenguaje y la subjetividad, que están formando parte de la base teórica y de la práctica de nuestro quehacer psicopatológico (aunque no importe saberlo o se ignore su valor y sus conceptos).

\section{A) REGISTRO DEL LENGUAJE}

Valor y lugar de la palabra

El niño habita, mora, vive al menos en dos espacios o lugares. Uno es su casa, su pueblo, su medio sociofamiliar, aquello que constituye su hábitat, su entorno físico.

Pero hay otro espacio, donde vive plenamente, y éste nos va a interesar y afectar en nuestro trabajo específico psicopatológico. Es aquél que en bellas y precisas palabras nos señala Heidegger: "El lenguaje es la casa del ser. En su morada habita el hombre" (19). O bien, como dice Wittgenstein: "El lenguaje es una parte de nuestro organismo" (20).

En tanto hablante ser, el niño está bañado en palabras, vive inmerso en el lenguaje. El poeta gallego Bernardino Graña al preguntársele si relataba en sus historias lo que aprendiera de su abuela y de su madriña, respondió: "Antes de nacer xa escoitaba o ambiente da taberna do meu padriño ... O'nacemento non é realmente o momento do parto ... Ao ventre da miña nai chegábanme as conversas, as tertulias da taberna do meu padriño..." (21).

Para Habermas: "En la intuición inmediata el espíritu es todavía animal, sólo con el lenguaje y en él se separan el ser de la conciencia y el ser de la naturaleza para la conciencia ... el lenguaje rompe el dictado de la intuición inmediata y ordena el caos de la diversidad de sensaciones en cosas identificables, les da nombre..." (22).

El niño una vez que pasa de ser infans -el que no habla- y entra en el lenguaje -que ya le precede y le inscribe como humano en el orden simbólico- trasciende el orden de la naturaleza para entrar en lo que Levi-Strauss (23) refiere como el orden de la cultura, propio y específico de lo humano, no reducido a un mero organismo, ni a la condición animal. 
ORIGINALES Y REVISIONES

\section{Pensamiento y lenguaje}

No hay pensamiento sin lenguaje. "El lenguaje -en palabras de M. Foucault (24)- representa el pensamiento [...] no es un efecto exterior del pensamiento, sino pensamiento en sí mismo". (Esto lleva a repercusiones clínicas, por ejemplo, acerca de la semiología de los delirios, o bien, si puede hablarse de diferencia entre trastornos del lenguaje y trastornos del pensamiento).

Continúa Foucault: "Lo que erige a la palabra como tal y la sostiene por encima del aullido, los gritos, o los ruidos, es la proposición oculta en ella. El niño salvaje del Aveyron, por ejemplo, no llegó a hablar porque para él, las palabras seguían siendo marcas sonoras de las cosas [...] podía pronunciar muy bien la palabra "leche" ante el tazón que le era ofrecido, pero esta palabra nunca se convirtió en signo representativo de la cosa" (Podría decir leche como el loro habla, pero por la lingüística sabemos que no hay que confundir habla y lenguaje).

En el niño psicótico hay una falla simbólica en tanto la palabra no remite a lo que metaforiza o simboliza en el registro del lenguaje, es decir, a lo que constituye la representación. La palabra queda cosificada, petrificada, en su literalidad.

Es el caso de una madre de un niño diagnosticado de Asperger que refería cómo su hijo tomaba las frases al pie de la letra, de tal forma que si le decía que iba a "echar un ojo a la sartén" en la cocina donde estaba haciendo la comida, el niño se angustiaba porque su madre lo echase realmente. O cuando le decía que tal equipo de fútbol jugaba en casa, le respondía que en su casa no podía ser, que jugaban en el estadio.

Queda lo dicho en un puro decir, literal, sin relación significado/significante como signo lingüístico, sin hacer cadena significante que remita al orden simbólico propio de lo humano y que lo diferencia de la mera señal, o de la simple comunicación animal. Ha perdido lo metafórico como esencia del lenguaje.

Lo que significa la diferencia entre habla y lenguaje puede sernos muy útil para comprender y no confundir algunas cosas en la psicosis, el autismo, lo deficitario, etc. Estos conceptos recogidos de la lingüística y aplicados a la clínica son importantes para entender lo que hacemos en nuestra práctica.

En este sentido ya nos alertaba Castilla del Pino cuando afirmaba: "Si se piensa que los síntomas de los cuadros psiquiátricos los detectamos porque se nos hablan, resulta incompresible que se pueda hacer psicopatología ignorando la lingüística, ciencia que enriquece el saber psiquiátrico" (25).

\section{Efectos de la palabra}

De la importancia de la palabra y sus efectos dan cuenta hoy las neurociencias. Así, E. Kandel -Premio Nobel de Medicina 2000- afirma: "En la medida que nuestras palabras producen cambios en la mente de nuestros pacientes, las intervenciones psicoterapéuticas producen cambios en el cerebro ... imágenes 
cerebrales realizadas en pacientes antes y después de someterse a psicoterapia o psicoanálisis demuestran que el cerebro se reorganiza plásticamente tras el tratamiento ... y concluyen, que ya no pueden existir dudas de que la psicoterapia puede propiciar cambios detectables en el cerebro" (26).

Ya en la antigüedad, Platón señalaba como la palabra era Pharmakon -veneno o medicamento- según la intención cómo se emplee, puesto que la palabra modifica la physis de quien la oye (27) (observación que todos hemos experimentado de como una palabra puede abatirnos o hundirnos o puede estimularnos y animarnos).

Si se hace hincapié en el valor e importancia del lenguaje, es porque es un instrumento específico y diferencial de lo humano y es de esto de lo que vamos a disponer para nuestro trabajo psicopatológico: un saber escuchar como clínicos. El niño habla, hay que escucharlo y no una escucha con el embeleso de la seducción.

Hemos de dar al niño un lugar propio en la clínica, abrirle a una demanda, a una escucha, a un espacio, donde pueda recoger y elaborar su decir, su historia, su patología. Es algo suyo -aunque venga por la vía de encargo o traído por otro - hay que escucharlo, porque para él, su sufrimiento es lo más importante en ese momento; a veces, lo único que tiene y de lo que dispone en el mercado de los valores y de los intercambios afectivos. Y cabe, quizás, que note que es la primera vez que alguien está interesado por su sufrimiento psíquico.

\section{B.) LA SUBJETIVIDAD}

El otro registro e instrumento para comprender y trabajar en la clínica psicopatológica es la subjetividad.

\section{La naturaleza y la cultura}

El niño en el proceso de su existir y de su ser, rompe con el orden de la naturaleza y el instinto, deja de ser mero organismo, mero cuerpo biológico (órganos, vísceras, hormonas, etc.), para inscribirse todo ello en el orden de la cultura y de lo simbólico, donde rigen saberes y leyes propias, objeto de un conocimiento diferenciado, específico y particular de lo subjetivo, que no se agota en las ciencias físico-matemáticas, ni en las leyes de la naturaleza.

El niño en tanto humano, no responde a unas leyes naturales ni instintivas ya dadas, inscritas y determinadas, que le diseñan y marcan un lugar y su papel en el mundo, como en el caso del animal y la planta.

A esta indeterminación de la especie humana no regida por las leyes de la naturaleza -"La naturaleza peculiar del hombre es la sociedad", nos dirá $\mathrm{M}^{\mathrm{a}}$ Zambrano (28)-llamémosle por su nombre, la libertad, es lo que hace necesario la existencia de normas que no son puramente naturales, sino lingüísticas (29). 
ORIGINALES Y REVISIONES

Como lo describe Dostoievski: "La mosca, la planta, el rayo de sol, etc., saben cuál es su lugar y participan del coro común y siguen unas leyes marcadas, mientras que sólo el hombre es un proscrito" (30) (está fuera de las leyes de la naturaleza).

Para Ortega y Gasset (31): "Esa vida que nos es dada no nos es dada hecha, sino que cada uno de nosotros tiene que hacérsela, cada cual la suya. Esto no acontece con el animal o la planta o la piedra, a ellos les es dado su ser prefijado y resuelto [ ] Por eso vida, en el sentido de vida humana, en el sentido radical de la palabra vida, se la entiende cómo biografía y no como biología" (Por ello al hacer una historia clínica es importante que nos cuente su biografia).

El que el hombre no se reduce al instinto, puede hacer comprender por qué puede atentar contra sus más primarios y básicos instintos: la vida, el hambre, el placer, etc. El hombre no queda reducido a la mera necesidad, sino que lo atraviesa el deseo.

\section{La vulnerabilidad constitutiva}

E. Fromm nos señalaba: "Como el hombre -el niño- es el animal más desamparado y desvalido, pero esta debilidad biológica -no limitada, ni fijada al instinto ni a la naturaleza- constituye la base de su fuerza, la causa primera de sus cualidades humanas" (32). (Importante entender esto para no confundir la vulnerabilidad como una anomalía).

El niño, el hombre, al estar carente, descarriado y desvalido, en dependencia del otro, le hace abrirse al deseo y al conocer, forjarse una existencia singular, consustancial con su realidad, "...la capacidad y desazón de sentirse perdidos, es su trágico destino y su ilustre privilegio” nos dirá Ortega (31).

Cada etapa que de niño al adulto recorre el hombre, le deja inconforme y perplejo y esta perplejidad le hace encontrar soluciones nuevas. Su vulnerabilidad constitutiva le hace capaz de buscar y resolver.

No hay una forma única, dada, fija y estructurada de resolver este desvalimiento y extravío, esta dependencia, este extrañamiento y esta incertidumbre propias del ser humano. La respuesta -como el sistema inmunológico que reacciona en relación a los patógenos que encuentra- es de cada uno, en el encuentro con la vida, subjetiva, singular, particular, personalizada, del caso por caso y se va a modificar en relación con las circunstancias y hechos de la vida.

La infinita diversidad de cada uno, es una característica de la existencia en tanto sujetos. La propia medicina tiende a los tratamientos personalizados. La subjetividad no puede tener una medida, una homologación o unos parámetros generales y universales. No hay escalas, cuestionarios, test, ítems, que reflejen un saber de lo singular, de lo subjetivo, de lo particular, del caso por caso, de lo específico. "No hay sino enfermedad individual: no porque el individuo re- 
acciona sobre su propia enfermedad, sino porque la acción de la enfermedad se desenvuelve, por derecho propio, en la forma de la individualidad" (33).

\section{Estatuto de lo subjetivo - los correlatos neuronales}

La subjetividad, siguiendo la reflexión de F. Pereña (14), "Nace de las experiencias del vínculo que no pueden codificarse y que hace que un niño haga una experiencia particular de una misma situación o de un mismo acontecimiento de como lo hace otro niño..." y añade, "No hay un correlato neuronal del yo de la subjetividad ... la actividad neuronal no origina la experiencia subjetiva. A los llamados neurotransmisores se les llama neuromoduladores ya que modulan la actividad en función de la vivencia de una situación o acontecimiento determinado. Esta modulación tiene que ver con el estado de ánimo o los modos particulares del ser afectados..." (los vínculos afectivos, las experiencias emocionales, los intercambios, etc.).

Para C. Moya, "Los conceptos de lo mental son realmente peculiares. No son simplemente distintos de los neurofisiológicos, sino que la atribución en primera o en tercera persona se rige por criterios distintos" ... "Yo no poseo especial autoridad con respecto a los estados de mi cerebro. De hecho un neurólogo es más competente que yo para determinarlos" ... "Pero este mismo neurólogo habrá de confiar en mis declaraciones para saber si tengo dolor cuando me implanta un electrodo" ... "tiene sentido que dos o más personas están observando el mismo proceso cerebral, pero no que dos o más personas están informadas de la misma experiencia interna" ... "los términos mentales no sólo tienen un significado diferente de los términos neurofisiológicos sino también una lógica diferente" ... "Si yo afirmo sinceramente que no tengo dolor y otra persona se empeña en atribuírmelo observando mi cerebro, no estamos hablando de lo mismo. La palabra dolor habrá cambiado de significado en boca de esta persona" ... "que una propiedad llamada dolor distinta de lo que ahora entendemos por dolor, fuese un estado del cerebro será tal vez un hecho interesante, pero no una respuesta al problema de la naturaleza de la mente..." (34).

Podemos visualizar las imágenes cerebrales que muestran las zonas neuronales estimuladas al oír una melodía, pero serán los pacientes quienes saben de la calidad, y de la vivencia de lo que sienten al escuchar dicha melodía, así como los sentimientos complejos y diversos que pueden darse en cada uno de los sujetos (35).

\section{III.- La clínica en S.M.I.}

\section{A) PREVENCIÓN}

Los conceptos señalados en los registros anteriores dan pie para entender la prevención en salud mental infantil, sobre todo para cuestionar una cierta idea de la prevención que se basa en la vulnerabilidad como concepto equívoco y confuso. 
ORIGINALES Y REVISIONES

$\mathrm{Al}$ analizar la prevención en salud mental infantil es necesario precisar:

$\left.1^{\circ}\right)$ Vulnerabilidad y resiliencia

No se puede hablar de prevención tomando como base el criterio y concepto de vulnerabilidad tal y como viene entendiéndose como algo anómalo y alterado.

La vulnerabilidad es intrínseca y le confiere al ser humano la capacidad de buscar y forjarse la construcción de su ser y de su identidad, "Es la base de su fuerza y la causa primaria de sus cualidades humanas" dice E. Fromm (32). Por lo tanto habrá que rescatar el concepto de resiliencia que cuadra más para entender la prevención, que no el de vulnerabilidad tomado éste como algo anómalo y ajeno a la esencia humana.

Resiliencia entendida como la capacidad de resistencia, tal como lo describe B. Cyrulnik (36): "La capacidad de resistir las magulladuras de las heridas psicológicas y el impulso de reparación psíquico que nace de esa resistencia"... "el proceso de resiliencia permite a un niño herido trasformar su magulladura en un organizador del yo, a condición de que a su alrededor haya una relación que le permita realizar una metamorfosis".

\section{$\left.2^{\circ}\right)$ Lo preventivo en salud mental}

La demanda, el saber, el sufrimiento, el mundo inconsciente, el síntoma, lo subjetivo, lo aleatorio y contingente, etc. no entran en el registro de lo medible, cuantificable y objetivable, ni de lo homogéneo y homologable por la bioestadística.

López Ibor señalaba como, "El conocimiento científico se basa en la búsqueda de lo que es igual en los fenómenos, en la analogía, en la relación de causalidad"... "en lo psíquico esto no es posible, falta lo que hay de igual en ellos"... "como la imagen de Heráclito, la corriente de lo psíquico, es como un río que nunca es igual en dos momentos consecutivos" (37).

En los modelos preventivos de salud mental no podemos aplicar mecánicamente una prevención como si de una víscera, un órgano, una función fisiológica, o un objeto, se tratase.

El Premio Nobel de Física, R. Feynman (38) al referirse a los cambios en la física y en la ciencia, explicaba: "Otro cambio muy importante en las ideas de la ciencia que trajo la mecánica cuántica es que no es posible predecir exactamente lo que va a suceder en cualquier circunstancia [...] la naturaleza tal como la entendemos hoy, se comporta de tal modo que es fundamentalmente imposible hacer una predicción precisa de qué sucedería exactamente en un experimento dado" . Esta misma idea la encontramos reflejada en el principio de incertidumbre de Heisenberg o en el teorema de Gödel.

Un falso mimetismo del modelo médico-biológico de prevención no tiene en cuenta lo específico y diferencial en salud mental, como es lo subjetivo, lo 
singular, lo aleatorio, lo contingente, el caso por caso... donde lo llamado preventivo tiene otros modelos y métodos de actuación.

Por supuesto que hay, por otro lado, necesidad de protección y cuidados: del maltrato, del abandono, de la explotación, de los derechos del niño, de su salud y de su bienestar, etc.

Ante la tendencia a medicalizar y patologizar los malestares de la vida cotidiana y los sufrimientos, no estará de más alertar y preguntase el porqué de esta deriva actual de potenciar toda la fragilidad y vulnerabilidad, ignorando y obviando la resiliencia.

Existe una compulsiva necesidad de ejercer el furor sanandi y protector a toda la sociedad, haciéndola cada vez más vulnerable, incapacitada, irresponsable, infantilizada, frágil y dependiente, y por ello, necesitada de expertos, técnicos, guías y salvadores, ante cualquier evento o hecho supuestamente traumático, reforzando así la falta de decisión e iniciativa, de creatividad y de autonomía y de solidaridad, favoreciendo por contra la pasividad, la dependencia y la sumisión.

Se hace actualidad el lema kantiano de la ilustración: ¡Sapere aude!, ¡Atrévete a saber, ten el coraje de servirte de tu propia razón!

\section{B) LA CLÍNICA EN SALUD MENTAL INFANTIL}

Con respecto a la práctica clínica, de forma sintética, es necesario destacar cuatro puntos de reflexión y debate.

\section{$\left.1^{\circ}\right)$ Las patologías del desarrollo madurativo}

Es preciso replantear las patologías del desarrollo madurativo tal como vienen entendiéndose. El criterio de maduración es de uso habitual en el mundo animal y vegetal, y en cierto orden biológico de los organismos de cada especie.

Como refiere F. Pereña: "Conceptualmente la maduración implica que hay un objeto que tiene en sí mismo su propio código de desarrollo o de normalización"... "en la medida en que la subjetividad es una alteración de la vida corporal y de la vida instintiva, la categoría de la maduración no es aplicable a la psicopatología" (39).

Siguiendo a D. Siegel, "La maduración genéticamente programada del sistema neuronal está sometida a la modulación de la experiencia"... "el yo -para F.Pereña (14)- no es un dato previo ni mental, ni corporal, ni espiritual, ni anatómico. Es un proceso. El cerebro con que nace un bebé con sus millones de neuronas, es un órgano que ha de desarrollarse y este desarrollo va a depender de cómo se modula, y esto es una actividad constante mientras se vive" (lo que se conoce por neurogenesis) "...la voz de la madre, el tacto, etc. crean una red relacional en permanente actividad, no como un proceso madurativo lineal, sino en constante relación con las emociones que vertebran las relaciones del sujeto con los demás. Esa permanente actividad convierte al sujeto en un ser alterado y un cerebro siempre pendiente nunca acabado" (Es la neuroplasticidad cerebral). 
ORIGINALES Y REVISIONES

Como señala el biólogo molecular y neurocientífico S. Rose (40): "Se hace difícil analizar el desarrollo en función de unas respuestas típicas de especies"... "hasta la generalización más simple está abierta a salvedades"..."entre los niños pueden darse unas desviaciones considerables en torno a la edad en que empiezan a caminar o a hablar sin que parezca haber ninguna diferencia posterior en su actuación"..."inevitablemente la experiencia individual se superpone a las generalizaciones que se aplican a una población, una característica más propia de la plasticidad del cerebro que de su especificidad".

La clínica del sujeto es una clínica de historias, del caso por caso, de lo contingente, de las biografías, de las diferencias específicas.

Ya nos alerta H. Arendt: "La conducta uniforme que se presta a la determinación estadística, por lo tanto a la predicción científicamente correcta, no es en modo alguno inofensiva"..."las ciencias del comportamiento -anulando la subjetividad- apuntan a reducir al hombre (en nuestro caso al niño) a un animal de conducta condicionada" (41).

\section{$\left.2^{\circ}\right)$ El saber psicopatológico y el sujeto de conocimiento}

¿Qué nos confiere especificidad como campo de conocimiento propio de lo psíquico infantil? Epistémicamente ¿qué nos da entidad propia como especialidad? ¿De qué sujeto nos ocupamos y qué saberes nos son propios? ¿Nuestros saberes se agotan en las ciencias de la naturaleza o bien, hay otros saberes no reducidos a lo científico, a las ciencias?

No caer en el error del cientificismo creyendo que la ciencia es el único saber. Hay conocimiento -saber- ciencia. La ciencia es una parte del saber y el saber es una parte del conocimiento.

El deslumbramiento cientificista -que no científico- ha llevado a que perdamos la riqueza y el rigor, la sutileza y finura de la semiología de los casos clínicos de la psiquiatría y la psicología clásicas; de la observación y la anamnesis; de la escucha y la mirada clínica; de la creatividad como modo de conocimiento, para quedarnos reducidos a la mirada por los aparatos y las pruebas, o las escalas, cuestionarios, test, etc. (En las consultas se mira hoy más al ordenador que al paciente).

No puede haber una ciencia de la belleza, de los valores, de lo justo e injusto, del amor, de los sentimientos, del bien y del mal, etc. A todo esto no le es aplicable lo científico, son otros saberes los que están en juego.

El Premio Nobel de Física Feynman, en relación con lo científico ironizaba: "La matemática no es una ciencia en el sentido de que no es una ciencia natural. La prueba de validez no es el experimento. Que algo no sea una ciencia no quiere decir necesariamente que sea malo. Por ejemplo, el amor no es una ciencia. Por lo tanto si se dice que algo no es una ciencia, no quiere decir que haya algo erróneo en ello; quiere decir simplemente que no es una ciencia" (38). 
Como dice $\mathrm{M}^{\mathrm{a}}$ Zambrano: "El saber es experiencia ancestral o experiencia sedimentada en el curso de la vida; experiencias vitales, no repetibles a voluntad como las que se efectúan en los laboratorios [...] Saberes que aparecen tras un acontecimiento extremo, enfermedad, muerte de un ser querido, un desengaño amoroso, o la alegría y la felicidad" (42).

Estas historias, estos saberes, son lo que, en tanto personales e intransferibles constituyen las biografías del sujeto, las vidas vividas, y dan cuenta de la verdad de la existencia y del sufrimiento psíquico. Verdad y sufrimiento que en tanto clínicos de lo "psi", vamos a "tratar" específicamente.

El físico y Premio Príncipe de Asturias, Etxenique, señala: "Podemos saber qué ley física gobierna la vida, pero ¿eso quiere decir que entendemos la vida, la belleza de un cuadro, el amor o el pánico en un estadio? Las propiedades de la vida como la belleza, la conciencia, etc. pueden no tener sentido a escala celular" (43).

O bien, como dice S. Rose (40): "Creer que la bioquímica es de algún modo más fiable que los sentimientos que comunica una persona será un ejemplo de lógica ex-juvantibus...” “...la bioquímica y la biología molecular no son lugares para buscar la sede del alma...”.

\section{$\left.3^{\circ}\right)$ La demanda en S.M.I.: La escucha clínica}

En la consulta infantil por lo general el niño es traído. La demanda viene a través de lo que el síntoma representa para quienes se ocupan del niño (padres, escuela, medio social, etc.).

Pero esta demanda, como toda demanda clínica, habrá que estudiarla, evaluarla, elaborarla, no tomarla al pie de la letra. Habrá que tener en cuenta en dicha demanda, el sufrimiento del niño y lo que para él representa ique en el intento de salvarlo, no lo arrojemos con el agua sucia!

Hay que escuchar la trama de historias que entretejen el lugar del niño, las historias de sus padres y familia, el medio, la escuela, etc. Pero hay que darle a él también su lugar, para que construya su relato, su decir, su biografía, su malestar...

El niño habla, hay que escucharlo -además y también de a quien lo trae-. No substituir su relato por la deriva actual de que antes de oír su historia, se le apliquen escalas, cuestionarios, pruebas, test, etc., en busca de una etiqueta o un diagnóstico previo.

Hay que construir una historia, una anamnesis. Una historia clínica que dé cuenta de su sufrimiento y de su dolor, de su deseo y de su goce.

Construir en la historia clínica, la biografía que recoja su relato, lo que el paciente narra de sí mismo, de su realidad, de su verdad. No la historia que busca cuadrar los sintomas y la biografía, con un saber y una verdad ajenos: la de la enfermedad catalogada, externa y prefijada.

Una historia que no sea de preguntas que sólo escuchan lo que encaja y se adapta al texto del diagnóstico, a los ítems de la enfermedad abstracta. En el fon- 
ORIGINALES Y REVISIONES

do, de esta forma, se asigna al paciente una realidad biográfica que responde más a la entidad mórbida preestablecida, general y universal, que a la particularidad, lo subjetivo y lo específico del caso por caso.

Se va a aplicar una identidad atribuida en tanto diagnóstico que debe aceptarla como condición de su curación (la llamada conciencia de enfermedad). Esta imposición de la verdad médica como omnipotencia del poder disciplinario (44) en tanto realidad impuesta, con la presunción de un saber universal y abstracto ha escotomizado la propia historia y biografía del sujeto, y no atiende al significado que para él tiene su malestar o sufrimiento psíquico.

Como refiere Gadamer: "La anamnesis, el recuerdo, es una forma del pensamiento, del logos, es decir, de la búsqueda..." (45).

$\left.4^{\circ}\right)$ La patologización de las conductas y el reduccionismo de la psicopatología infantil: La abdicación de las credenciales clínicas.

La creciente patologización de los malestares de la vida cotidiana y del sufrimiento, hace que cualquier reacción vivencial, cualquier conducta o malestar propio del niño, sea tomada como patológico.

El simplismo y reduccionismo al que se ve abocada la clínica actual, lleva a confundir y hacer pasar:

- El síntoma por la enfermedad

- La parte por el todo

- Las causas por sus efecto

Así nos encontramos, como la clínica se está reduciendo a un prontuario de items que protocolizados y envasados como guías clínicas, definen un trastorno o enfermedad, al cual se le asigna un tratamiento ya establecido (se cumpliría así el sueño del recetario o del manual de instrucciones).

El profesor Berrios en su reflexión acerca de la M.B.E. hace una acerada crítica de las guías y protocolos en Psiquiatría: "Dichas guías en la práctica destruirían la espontaneidad terapéutica de la Psiquiatría y cambiarían el antiguo arte de prescribir, que pasaría de ser creativo y flexible a mecánico y uniformado"... "Finalmente ni siquiera requeriría que los prescriptores psiquiátricos estuvieran medicamente cualificados" ..."esto conllevaría que la vieja relación médico/paciente y el paciente que sufre, han desaparecido para siempre" (46).

La presidenta del Comité de Ética del British Medical Journal, Iona Heath, al referirse a los protocolos afirmaba: "La atención médica parece cada vez más producto de protocolos empíricos cuya naturaleza hace que se considere a los pacientes como unidades estándares de enfermedad. Esos protocolos no tienen manera de dar cabida al relato de cada individuo, a los valores, las aspiraciones y las propiedades de cada persona diferente y a las formas en que los mismos van cambiando con el tiempo" (47). 
En la clínica psicopatológica infantil, los trastornos o enfermedades de los manuales diagnósticos, son en general meros sintomas, que en el empobrecimiento y el simplismo al que se está reduciendo la clínica, se los erige en estructuras o cuadros clínicos. Nunca la medicina -la clínica- estuvo tan lejos de sus credenciales: no confundir síntoma con enfermedad (no ser cazasíntomas).

En última instancia, este recorte de la clínica en sintomas, sigue sin abordar la realidad de las estructuras clínicas y la expresión del sufrimiento en el niño.

En la línea de lo referido, basten dos ejemplos sacados de los manuales diagnósticos: el T.G.D. (Trastorno Generalizado del Desarrollo), esa etérea entidad nosológica cajón de sastre de confusión y mezcolanza; el T.D.A.H. (Trastorno Hipercinético y Déficit de Atención) erigido en categoría diagnóstica eminente y unidad de destino en lo universal de la Psiquiatría Infantil, llegando en algunos servicios o unidades de salud mental infantil a ser el $70 \%$ u $80 \%$-a veces más-de los diagnósticos, convirtiéndose de esta forma en la prácticamente única entidad de la psicopatología infantil (48).

La hipercinesia y el déficit de atención (que, claro está, existen, sino no existirían la motricidad ni la atención) en tanto síntomas o signos, remiten a una multiplicidad de expresiones, estructuras o cuadros clínicos, pero si se toman como entidad clínica diagnóstica única, se obvia o ignora el saber de su expresión y de su etiopatogenia, es decir, de qué entidad o cuadro clínico se trata en realidad (pura semiología).

Expondré otro ejemplo de cómo se desvirtúa y condiciona la clínica infantil, tan sólo mostrando cómo se presentan o nombran hoy día en las consultas, los problemas que puede presentar el niño y como esto va a determinar la clínica. "Hay que llamar otra vez a las cosas por su nombre" (R. Argullol).

Rabietas- perrenchas- pataletas

Agitación

No aguantarse- hacer lo que le da la gana ......... Impulsividad

Caprichoso- trasto- rebelde....

Disruptivo

Contestón- desafiante- oposicionista......

Negativismo desafiante

Voluble- incontinente- prontos

Explosivo intermitente

Desasosiego- nervioso- malestar....

Ansiedad

Inquieto-no para- como una moto

Hipercinético

Distraido- no se centra- en las nubes

Déficit de atención

El venir a consulta con una u otra forma de presentar el problema del niño, va a predisponer toda una práctica clínica y diagnóstica por consecuencia.

$Y$ esto no es una banalidad o anécdota ingeniosa. El nombrar las cosas patologizándolas, patologizar las conductas y comportamientos, supone que el hacer las cosas bien o mal, el portarse adecuadamente, no será efecto de la probidad 
ORIGINALES Y REVISIONES

moral, del esfuerzo, de la templanza, del dominio o de la libre elección, sino de los neurotransmisores, o de la genética, las lesiones cerebrales, etc.

Confundir las conductas, patologizándolas, (claro está que hay conductas patológicas que hay que evaluar y tratar), cuando se patologizan sin serlo, supone que los esquemas ordenadores de las buenas o malas acciones, se substituyen por trastornos cerebrales o mentales. "La retórica de enfermedad y terapias sustituyen la libertad del sujeto para decidir sobre su vida, para responder de sus actos" (49).

Impera así la inocencia y la impunidad como horizonte moral. La desresponsabilización generalizada. La exoneración de la persona del compromiso de su propia vida.

Retomando el proverbio de A. Machado, "Es el mejor de los buenos quien sabe que en esta vida, todo es cuestión de medida: un poco más, algo menos", se podría añadir:

Un poco más de rigor científico, de semiología, de escucha biográfica y de clínica psicopatológica.

Algo menos de pereza intelectual, de cazasíntomas y de patologizar las conductas y el sufrimiento.

BIBLIOGRAFÍA

(1) Berrios, G.Vieja y nueva Psiquiatría. Maristán, 1994, III, 6-7; p.36

(2) Kant, I, Crítica de la razón pura. $3^{\text {a }}$ Ed. Madrid: Taurus. 2010; p.310

(3) Spinke Jonze. El Mundo (10-XII-2009)

(4) Ariès, $\mathrm{Ph}$. El niño y la vida familiar en el antiguo régimen. Madrid: Taurus. 1987

(5) Lloyd de Mause, Historia de la infancia. Madrid: Alianza. 1982

(6) Clark, E. La publicidad y su poder. Barcelona: Planeta. 1988; p.172

(7) Bauman, Z. Vida de Consumo. Madrid: Fondo de Cultura Económica. 2007, p.91

(8) Niños explotados. El País (24-I-2012)

(9) Winnicott, D.N. El niño y el mundo exterior. B. Aires: Paidos. 1980; p.172

(10) Yourcenar, M. Con los ojos abiertos. Barcelona: Plataforma ed. 2008; p.40

(11) American Psychiatric Association (APA). Diagnostic and Statistical Manual of Mental

Disorders, $4^{\text {th }}$ edition. Washington, DC: American Psychiatric Association. 1994

(12) Grass, G. El País (26-X-1997)

(13) Ricoeur, P. El País (28-IV-1991)

(14) Pereña, F. Los límites de la psicopatología infantil. LXIII Congreso de la Sociedad de Pediatría de Galicia. Octubre 2012

(15) Gracián, B. El Criticón. $7^{\text {a }}$ Ed. Madrid: Espasa Calpe. Austral. 1968; p. 44-45

(16) Del Campillo y Cossío, J. Grandes autores asturianos. Hércules-Astur. 1992; p.258

(17) Ortega y Gasset, J. La rebelión de las masas. Círculo de lectores. 1997; p.86

(18) Bunge, M. Filosofía para médicos. Barcelona: Gedisa. 2012; p.15

(19) Heidegger, M. Carta sobre el humanismo. $5^{\text {a }}$ reimpresión. Madrid: Alianza. 2009; p.11

(20) Citado por H.Arendt en Vida del Espíritu. Barcelona: Paidós. 2002; p.77 
(21) Graña, B. El País (5-X-2007)

(22) Habermas, J. Ciencia y técnica como ideología. Madrid: Tecnos. 1992; p.27

(23) Lévi-Strauss, C. Las estructuras elementales del parentesco. Barcelona: Paidós. 1981

(24) Foucault, M. Las palabras y las cosas. Madrid: Siglo XXI. 1978

(25) Castilla del Pino, C. Historia crítica de la Psiquiatría en el S.XX. Revista Asoc. Esp. Neuropsiquiatría. 2007, XXVII,99; 114-115

(26) Etkin, Poland, Kandel, E. Journal of Neuropsychiatry and Clinical Neurosciences. 17, $2005 ; 145-148$

(27) Laín Entralgo, P. La curación por la palabra en la antigüedad clásica. $1^{\text {a }}$ Ed. Barcelona: Anthropos. 1987; p.106

(28) Zambrano, $\mathrm{M}^{\mathrm{a}}$. Sobre el problema del hombre. Anthropos -suplemento 2- Marzo-Abril $1987 ;$ p. 100

(29) Klappenbach, A. Claves de la razón práctica. 2010, $n^{\circ}$ 207; $p .81$

(30) Dostoievski, F. El Idiota. $3^{\text {a }}$ Ed. Barcelona: Bruguera. 1979; p.506

(31) Ortega y Gasset, J. El hombre y la gente. Madrid: Alianza, 2010

(32) Fromm, E. Ética y psicoanálisis. 12ª reimpresión. Madrid: F.C.E. 1980; p.53-54

(33) Foucault, M. El nacimiento de la clínica. $1^{\text {a }}$ Ed. México: Siglo XXI. 1966; p.240

(34) Moya, C. El sujeto enunciado. En Tiempo de subjetividad. Cruz, M (Compilador) Barcelona: Paidós. 1996; p.168-169

(35) Precht, R.D. Amor. Un sentimiento desordenado. Barcelona: Siruela 2011; p.182

(36) Cyrulnik, B. Los patitos feos. $3^{\text {a }}$ reimpresión. Barcelona: Gedisa. 2002

(37) López Ibor, J.J. La agonía del psicoanálisis. Buenos Aires: Espasa Calpe, Austral. 1951; p.141

(38) Feynman, R. Seis piezas fáciles. $4^{\mathrm{a}}$ Ed. Barcelona: Drakontos bolsillo. 2008

(39) Pereña, F. Apuntes para una psicopatología infantil. Rev. Asoc. Esp. Neuropsiquiatría. 2011; 31 (110); p. 255-269

(40) Rose, S. Tu cerebro mañana. Barcelona: Paidós. 2008

(41) Arendth, H. La condición humana. $3^{\text {a }}$ reimpresión. Barcelona: Paidós. 1998; p. 54-55

(42) Zambrano, $\mathrm{M}^{\mathrm{a}}$. Notas de un método. Madrid: Tecnos 2011; p.147-148

(43) Etxenique. El Mundo (9-XII-2009)

(44) Foucault, M. El poder psiquiátrico. Madrid: Akal. 2005

(45) Gadamer, H. El Estado oculto de la salud. Barcelona: Gedisa. 2011; p.127-128

(46) Berrios, G. Sobre la medicina basada en la evidencia. http:// www. psicoevidencias.es/ novedades/editorial/on-evidence-bases-medicine.html

(47) Healt, I. Ayudar a morir. Madrid: Katz. 2008; p.22

(48) Informe del Centro de Prevención y control de enfermedades de EE.UU. sobre el exceso de diagnósticos de IDAH. http://sociedad.elpais.com/sociedad/ 2013/04/02/actualidad

(49) Rendueles, G. Las drogas como metáfora tóxica. Goze, 2000. III, 9; p.21 